\title{
Tay Sachs disease carrier screening in schools: Educational alternatives and cheekbrush sampling
}

Alexandra A. Gason, $P h D^{1}$, Sylvia A. Metcalfe, $P h D^{1}$, Martin B. Delatycki, PhD ${ }^{1,2}$, Vicki Petrou, Dip Gen Couns ${ }^{2}$, Edith Sheffield, Grad Dip Gen Couns' ${ }^{2}$ Agnes Bankier, FRACP ${ }^{2}$, MaryAnne Aitken, PhD ${ }^{1}$

\begin{abstract}
Purpose: Tay Sachs disease carrier screening programs have been offered successfully worldwide since 1970 . The programs typically offer education, testing, and counseling to provide reproductive choices. One such program has been offered to Jewish school students in Melbourne since 1998. In a time of increasing public awareness of genetics, programs require continuous evaluation and updating. Methods: Over 2 successive years, a longitudinal evaluation involved students attending Jewish schools in Melbourne. Both qualitative and quantitative techniques were used to analyze alternative methods for education and sampling procedures. Comparisons involved (1) a computer-based resource versus an oral educational presentation and (2) blood sampling for enzyme and genetic testing versus cheekbrush testing for genetic sampling alone. Results: The education session was effective in significantly increasing students' knowledge $(10.5 \% \pm 1.2 \%, P<.0001)$ and decreasing their anxiety about being a carrier $(-12.2 \% \pm 1.6 \%, P<.0001)$. For the students, no significant differences were found between the computer-based resource and oral presentation. There were significantly more students accepting a carrier test and anxiety was lower when a cheekbrush test was offered compared with when a blood test was offered. Conclusions: Computer-based instruction is equally effective, in addition to offering advantages of self-paced learning and minimization of human resources as an oral presentation within a genetic carrier screening program. Cheekbrush sampling is preferred to blood sampling and should be implemented into current practices for offering genetic screening programs. These results present alternatives to practices for genetic screening reflecting the current developing technology. Genet Med 2005:7(9):626-632.
\end{abstract}

Key Words: education, genetic, screening, Tay Sachs disease, schools

The translation of knowledge and understanding of inherited medical conditions to public health benefit is commonly realized through population genetic screening programs. ${ }^{1}$ Tay Sachs disease (TSD) carrier screening programs, first introduced in Baltimore, Maryland, in 1970, ${ }^{2}$ offer education and carrier testing to provide reproductive information for individuals. TSD is a fatal, neurodegenerative condition that is inherited in an autosomal recessive manner. The increased prevalence of TSD carriers in the Ashkenazi Jewish community has seen a worldwide effort to introduce screening programs and has resulted in a greater than $90 \%$ reduction in the incidence of disease in communities where screening is offered. ${ }^{3}$ The programs are now a prototype for population genetic screening programs. However, recent genetic research is making a sub-

From the ${ }^{1}$ Murdoch Childrens Research Institute, Bruce Lefroy Centre for Genetic Health Research, Department of Paediatrics, University of Melbourne, Royal Children's Hospital; and ${ }^{2}$ Genetic Health Services Victoria, Royal Children's Hospital, Victoria, Australia.

MaryAnne Aitken, PhD, Genetics Education and Health Research, Murdoch Childrens Research Institute, 10th Floor, Royal Children's Hospital, Flemington Rd, Parkville, VIC, 3052, Australia.

Received: June 1, 2005.

Accepted: September 9, 2005.

DOI: 10.1097/01.gim.0000187162.28070.a7 stantial impact on health improvement and disease prevention, ${ }^{4}$ and review of current practices in offering population genetic screening programs is appropriate.

Delivery of effective education for cystic fibrosis (CF) carrier screening has been explored with a study comparing video with written information. ${ }^{5}$ Within TSD carrier screening programs, consideration of alternative educational approaches has not been made. Rather, in terms of alternative procedures, debate in the literature surrounds the use of enzyme testing and/or DNA mutation analysis for detection of TSD carriers in the Ashkenazi and non-Ashkenazi Jewish populations. Screening has traditionally been by enzyme assay, ${ }^{6}$ and since the characterization of the HexA gene in $1985,{ }^{7}$ mutation detection has been possible. Three mutations account for more than $98 \%$ of mutant alleles in the Ashkenazi Jewish population: 1,2,7,8 + TATC, ${ }^{8} 1421+1 \mathrm{G} \rightarrow \mathrm{C},{ }^{9,10}$ and Gly269Ser. ${ }^{11}$ The arguments in the literature have solely centered on the issue of sensitivity of the two testing methods. A combination of methods is suggested to provide optimum sensitivity and specificity; ${ }^{12}$ however, Bach and colleagues found that analysis of the three common mutations in the Ashkenazi Jewish population detected all carriers, whereas enzyme assay did not. ${ }^{13}$ The sampling procedure is often overlooked in this debate. Enzymatic analysis requires a blood sample to be drawn; however, DNA mutation 
analysis alone allows an individual sample of cells to be collected in a noninvasive manner, such as from the inside of the cheek with a brush.

There have been ongoing modifications made to the schoolbased TSD carrier screening program in Melbourne since its inception in $1998 .{ }^{14}$ These have reflected the availability of newer technologies, specifically in the area of education and procedures for sampling and testing. Previously we published information on the design and development of a computerbased resource and compared knowledge between students using this resource and those given the traditional oral presentation. ${ }^{15}$ This article presents data collected over a 2 -year period and includes the measurement of several parameters along with qualitative, interview data and a comparison between sampling procedures.

This study compares two alternative educational interventions on evaluation outcomes and examines the effect of two alternative forms of genetic sampling procedures (blood and cheekbrush) on uptake of testing and evaluation outcomes.

\section{METHODS}

This study was approved by the Human Research Ethics Committee, Royal Childrens Hospital, Melbourne, and informed consent was obtained from participants.

\section{Participants}

Students in their penultimate school year (aged 14-17 years) attending two Jewish day schools in Melbourne were offered TSD carrier screening ${ }^{14}$ and were invited to participate in the evaluation.

\section{Educational intervention}

Students were randomly divided into two groups to receive a computer-based instruction (CBI) resource ${ }^{15}$ or an oral presentation with visual aids. ${ }^{14}$ The content of the CBI resource may be found at www.taysachs.net.

\section{Sampling procedure}

Until and including 2002, carrier screening was performed by enzyme analysis combined with mutation detection. ${ }^{16}$ In 2003, sampling and testing were changed to cheekbrush sampling with mutation analysis of the three common mutations in the Ashkenazi Jewish population.

\section{Evaluation protocol}

Both quantitative and qualitative methods of evaluation were used for maximum evaluation rigor (Fig. 1). Three questionnaires were completed over a period of 6 months in 2 successive years (pre-education [Qe1]; posteducation on the day of testing [Qe2]; and at the time that test results became available [those tested and not tested] [Qe3]). Interviews were conducted with the students on the day of testing and when carrier test results were made available.

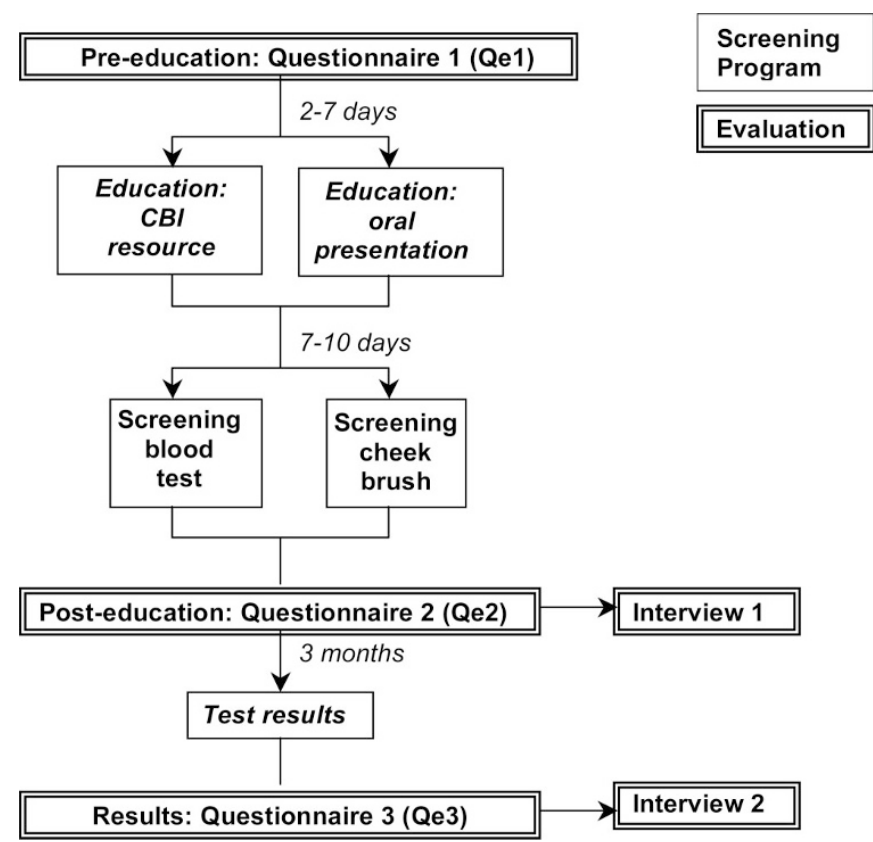

Figure 1. The evaluation process used a combination of quantitative and qualitative research methods.

\section{Questionnaires}

The questionnaires used in this study underwent a process of construction and validation. Briefly, this involved content validation with a panel of experts (Delphi technique) followed by an iterative process of pilot testing and statistical analyses. The questionnaires were matched and de-identified to allow longitudinal analyses. The sections included demographics, knowledge, attitudes, and anxiety. All scores were calculated as percentage scores. The knowledge score was calculated as the percentage correct from seven knowledge questions regarding the clinical and genetic features of TSD. Attitudes related to the students' level of interest in genetic technologies and personal importance of genetic testing. Anxiety was measured with the STAI short form. ${ }^{17}$ The questionnaires can be found at www.mcri.edu.au/TSD.

\section{Data analysis}

For questionnaire data, descriptive statistical techniques were used to describe the characteristics of the study participants. Chi-square analyses, analyses of variance, and $t$ test repeated-measures design of general linear model with post hoc tests (Dunnett T3) were used to analyze the data for significance. Estimated marginal means and mean \pm standard error of the mean are reported. All statistical procedures were performed using the statistical software package SPSS (Windows, version 11.0; SPSS Inc., Chicago, IL).

For interview data, thematic analysis was performed on interview transcripts using the qualitative data analysis software package Nvivo (QSR International, version 1.2, Melbourne, Australia). 


\section{RESULTS}

\section{Participants}

Of the 476 students in their penultimate year of schooling attending the two Jewish day schools in 2002 and 2003, 450 $(94.5 \%)$ were enrolled in the study. This was either the longitudinal study with Qe1, 2, and $3(\mathrm{~N}=349,77.5 \%)$ or anonymously completing Qe2 only on the day of testing $(\mathrm{N}=101$, $22.4 \%)$. Overall, there were no statistical differences found between those in the longitudinal study and those only completing Qe2 in terms of knowledge, attitudes, and anxiety (data not shown). Table 1 presents the characteristics of the students participating in the questionnaire study.

Interviews: A total of 38 students participated in an interview for this study.

\section{Effects of the educational intervention on evaluation outcomes}

The comparative analysis on evaluation outcomes was between the oral presentation $(\mathrm{N}=148)$ and CBI resource $(\mathrm{N}=$ 150). Overall, there were no statistically significant differences between the educational interventions. Table 2 shows the estimated marginal means from Qe1 and Qe2.

There was an overall significant increase in knowledge for the whole group from before to after education $(10.5 \% \pm$ $1.2 \%, d f=762, P<.0001)$. However, no significant differ-

Table 1

Characteristics of the student group in the longitudinal study obtained from Qe1

\begin{tabular}{|c|c|c|}
\hline & $\mathrm{n}$ & $\%$ \\
\hline \multicolumn{3}{|l|}{ Age } \\
\hline 14 & 1 & 0.3 \\
\hline 15 & 8 & 2.3 \\
\hline 16 & 259 & 75.7 \\
\hline 17 & 74 & 21.6 \\
\hline mean \pm SEM & $16.2 \pm 0.03$ & \\
\hline \multicolumn{3}{|l|}{ Gender } \\
\hline Male & 165 & 48.1 \\
\hline Female & 178 & 51.9 \\
\hline \multicolumn{3}{|l|}{ Jewish Ancestry } \\
\hline Ashkenazi & 238 & 71.5 \\
\hline Sephardic & 12 & 3.5 \\
\hline Mixed & 50 & 15.0 \\
\hline Unsure & 33 & 10.0 \\
\hline \multicolumn{3}{|c|}{ Where did you hear of program } \\
\hline School & 84 & 51.3 \\
\hline Family & 43 & 26.2 \\
\hline Friends & 23 & 14.0 \\
\hline Other & 14 & 8.5 \\
\hline Total & 349 & 100.0 \\
\hline
\end{tabular}

SEM, standard error of mean. ences were found in the knowledge score at any time point between the educational intervention groups (Fig. 2A). Similarly, there was an overall significant decrease in the predicted anxiety about being a carrier after education $(-12.2 \% \pm 1.6 \%$, $d f=751, P<.0001$ ), with no significant differences found between the educational intervention groups (Fig. 2B). Attitudes toward genetic testing in general were not significantly different after education for the whole group and between educational intervention groups (Fig. 2B). Personal importance of genetic testing was not significantly different between educational intervention groups or as a whole group over the three time points (Fig. 2B).

Interview data complemented these questionnaire data with comments made by students shown in Appendix 1 (available online at www.geneticsinmedicine.org). In summary, students believed the education component to be important. Students identified advantages and disadvantages to both educational interventions, reflecting different learning styles. The CBI resource was quick and easy; however, the students had to take the initiative to look through the information. The oral presentation was informative; however, the pace of the presentation did not suit all students.

\section{Effects of the sampling procedure on evaluation outcomes}

\section{Test uptake}

A significantly higher proportion of students had a test for their TSD carrier status when the test used a cheekbrush (96.0\%, $\mathrm{N}=214)$ compared with a blood sample $(84.9 \%, \mathrm{~N}=$ $163 ; \chi^{2}=15.2, d f=1, P<.0001$ ) (Fig. 3).

\section{Evaluation outcomes}

Evaluation outcomes were measured at the time of testing (Qe2). When a blood test was offered to the students for determination of their TSD carrier status, the students having the test had a statistically higher knowledge level $(89.5 \% \pm 0.9 \%$, $\mathrm{N}=163)$ than the students declining the blood test $(80.5 \% \pm$ $3.7 \%, \mathrm{~N}=29 ; t=-3.3, d f=190, P=.001)$. For the cheekbrush test there was no significant difference found in the knowledge scores between students having (mean rank = $112.0, \mathrm{~N}=214$ ) or declining testing (mean rank $=112.5, \mathrm{~N}=$ 9; $P=1.0$ ). Rather, students having the cheekbrush test were significantly more favorable toward genetic technologies in general (mean rank $=113.6, \mathrm{~N}=213 ; \mathrm{Z}=-2.4, P=.02$ ), and they placed a greater personal importance on genetic testing (mean rank $=114.3, \mathrm{~N}=214 ; \mathrm{Z}=-2.7, P=.007$ ) than those declining a cheekbrush test (mean rank $=61.9, \mathrm{~N}=9$, and mean rank $=56.3, \mathrm{~N}=9$, respectively). Students having the blood test also placed a significantly greater personal importance on genetic testing $(64.8 \% \pm 1.6 \%, \mathrm{~N}=161)$ than the students declining the blood test $(55.8 \% \pm 5.0 \%, \mathrm{~N}=28 ; t=$ $-2.0, d f=187, P=.04)$. In terms of anxiety, having a blood test caused significantly more anxiety $(38.2 \% \pm 1.8 \%, \mathrm{~N}=$ $160)$ than not having a blood test $(20.9 \% \pm 4.4 \%, \mathrm{~N}=29 ; t=$ $-3.8, d f=187, P<.001)$. There was no significant difference in anxiety between those having a cheekbrush test (mean rank 
Table 2

Comparison of educational interventions on measured outcomes

\begin{tabular}{|c|c|c|c|c|c|c|}
\hline & \multicolumn{5}{|c|}{ Educational Intervention } & \multirow[b]{3}{*}{ Statistics } \\
\hline & \multirow{2}{*}{$\frac{\text { Overall }}{\text { mean } \% \pm \text { SEM }}$} & \multicolumn{2}{|c|}{ Oral Presentation } & \multicolumn{2}{|c|}{ CBI Resource } & \\
\hline & & $\mathrm{n}$ & mean $\% \pm$ SEM & $\mathrm{n}$ & mean $\% \pm$ SEM & \\
\hline \multicolumn{7}{|c|}{ Knowledge } \\
\hline Pre & $75.6 \pm 1.0$ & & $74.7 \pm 1.5$ & & $76.5 \pm 1.4$ & $\mathrm{p}=0.3(\mathrm{NS})$ \\
\hline Post & $87.0 \pm 0.8$ & & $86.4 \pm 1.1$ & & $87.6 \pm 1.2$ & \\
\hline EMM & & 148 & $80.5 \pm 1.1$ & 150 & $82.1 \pm 1.1$ & \\
\hline \multicolumn{7}{|c|}{ General attitude } \\
\hline Pre & $68.0 \pm 1.1$ & & $68.0 \pm 1.4$ & & $68.3 \pm 1.6$ & $\mathrm{p}=0.8(\mathrm{NS})$ \\
\hline Post & $68.0 \pm 1.0$ & & $67.5 \pm 1.3$ & & $68.2 \pm 1.5$ & \\
\hline EMM & & 145 & $67.8 \pm 1.3$ & 146 & $68.2 \pm 1.3$ & \\
\hline \multicolumn{7}{|c|}{ Importance } \\
\hline Pre & $66.8 \pm 1.5$ & & $67.4 \pm 2.0$ & & $65.6 \pm 2.1$ & $\mathrm{p}=1.0(\mathrm{NS})$ \\
\hline Post & $64.7 \pm 1.3$ & & $64.2 \pm 1.9$ & & $65.1 \pm 1.8$ & \\
\hline EMM & & 145 & $65.7 \pm 1.7$ & 147 & $65.8 \pm 1.7$ & \\
\hline \multicolumn{7}{|c|}{ Anxiety at time } \\
\hline Pre & $26.2 \pm 1.1$ & & $27.5 \pm 1.5$ & & $24.8 \pm 1.7$ & $\mathrm{p}=0.6(\mathrm{NS})$ \\
\hline Post & $28.4 \pm 1.3$ & & $29.1 \pm 1.9$ & & $28.4 \pm 1.7$ & \\
\hline EMM & & 142 & $27.9 \pm 1.5$ & 147 & $26.7 \pm 1.5$ & \\
\hline \multicolumn{7}{|c|}{ Predicted anxiety should they be a carrier } \\
\hline Pre & $68.4 \pm 1.3$ & & $68.4 \pm 1.8$ & & $68.4 \pm 2.0$ & $\mathrm{p}=0.3(\mathrm{NS})$ \\
\hline Post & $56.5 \pm 1.3$ & & $53.8 \pm 1.9$ & & $58.7 \pm 1.6$ & \\
\hline EMM & & 144 & $61.4 \pm 1.6$ & 146 & $63.5 \pm 1.6$ & \\
\hline
\end{tabular}

Pre- (Qe1) and post- (Qe2) education percentage scores and estimated marginal means are shown for each educational intervention and the student group overall.CBI, computer-based instruction; SEM, standard error of mean; NS, not significant; EMM, estimated marginal mean.

$=110.4, \mathrm{~N}=214)$ compared with those who declined testing (mean rank $=98.4, \mathrm{~N}=9 ; P=.5$ ).

Students who chose to have a blood test had a statistically higher knowledge score $(89.5 \% \pm 0.9 \%, \mathrm{~N}=163)$ than those who chose to have a cheekbrush test $(84.4 \% \pm 1.1 \%, \mathrm{~N}=214$; $t=3.5, d f=375, P<.0001)$. However, the difference in knowledge scores between both test procedures for the students declining testing was not significantly different (bloodmean rank $=19.1, \mathrm{~N}=29$; cheekbrush - mean rank $=20.8, \mathrm{~N}$ $=9 ; \mathrm{Z}=-0.4, P=.6$ ). There was no significant difference with respect to the general attitudes or personal importance of genetic testing between the blood and cheekbrush tests for those having testing or for those declining testing. Students having a blood test were significantly more anxious $(38.2 \% \pm$ $1.8 \%, \mathrm{~N}=160)$ than those having the cheekbrush $(21.2 \% \pm$ $1.3 \%, \mathrm{~N}=214 ; t=7.7, d f=305, P<.0001)$.

The students stated a primary and secondary reason for their decision on testing (data not shown). The major primary reason for having the test for both sampling procedures was "wanting to know their carrier status" (blood 80.4\%, N = 131 and cheekbrush $72.4 \%, \mathrm{~N}=155$ ), whereas the secondary rea- son was convenience (blood $36.2 \%, \mathrm{~N}=59$, and cheekbrush $35.0 \%, \mathrm{~N}=75$ ). Of students declining testing, the majority did so because they did not want to know at that point in their life (50.0\%, $\mathrm{N}=15$ for blood test, and 55.5\%, $\mathrm{N}=5$ for cheekbrush). Also the blood test itself was a deterrent for testing $(41.4 \%, \mathrm{~N}=12)$. These data are supported by the interview comments made by students (Appendix 2, available online at www.geneticsinmedicine.org).

\section{DISCUSSION}

The results of this study reviewing the practice of TSD carrier screening for students attending Jewish schools in Melbourne show that CBI is equally effective as an oral educational presentation and that cheekbrush sampling is the preferred sampling method.

The evaluation of the Melbourne TSD screening program encompassing the initial years of the program's implementation has been described. ${ }^{14}$ The evaluation described here, now including baseline data collection before education, can attribute outcome changes to a direct consequence of the educa- 
A

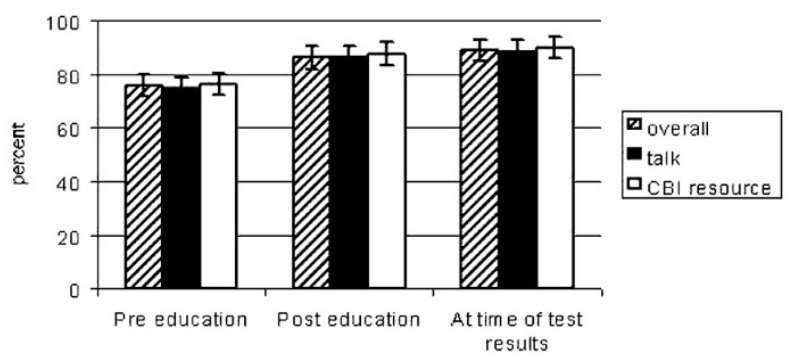

B

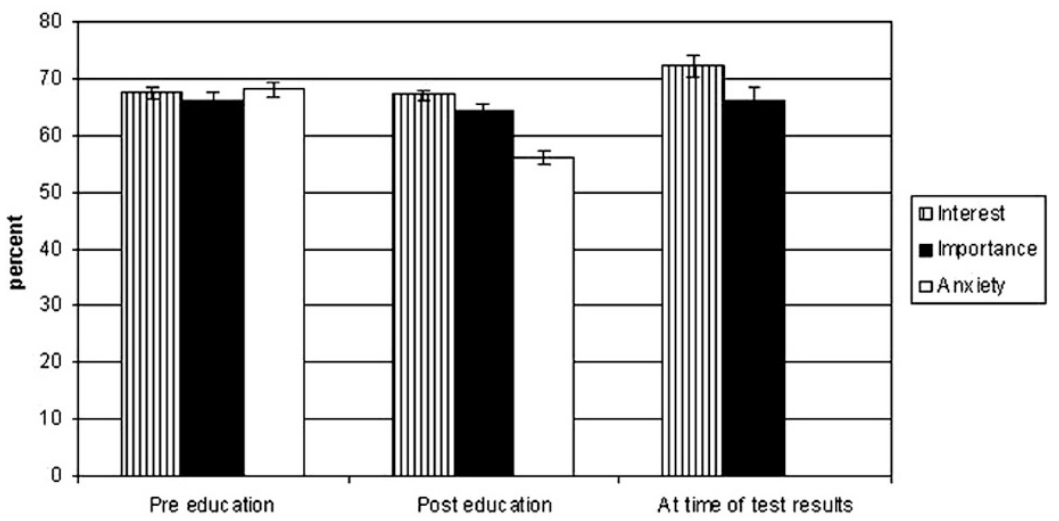

Figure 2. (A) Knowledge levels (mean $\% \pm$ standard error of mean) at each time point (Qe1, 2 , and 3 ) for the group as a whole and for each educational intervention group. The overall significant increase in knowledge from pre- (Qe1) to post- (Qe2) education is indicated.* The estimated marginal means (EMMs) from pre- to posteducation between educational intervention groups were not significant (Table 2). (B) Interest, importance, and anxiety before and after education and at the time of receiving results; scores (mean $\% \pm$ standard error of mean) for "interest in genetic testing," "personal importance of genetic testing," and "predicted anxiety of being found a carrier." There were no significant differences in the general attitudes toward genetic testing or in the personal importance of genetic testing, nor were there any differences between each educational intervention (Table 2) at any time point. There was a significant decrease in anxiety after the education session as indicated. ${ }^{*}$ The level of anxiety from pre- to posteducation between educational intervention groups was also not significant (Table 2).

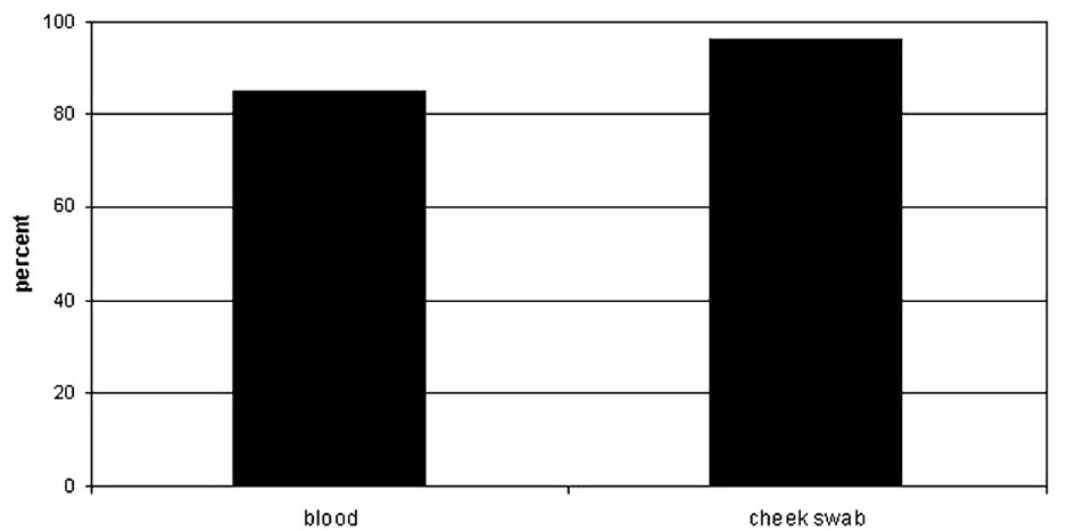

Figure 3. Test uptake for TSD carrier status. The proportion of students who had a carrier test was $84.9 \%(\mathrm{~N}=163)$ with blood sampling, whereas $96.0 \%(\mathrm{~N}=214)$ of students accepted testing with a cheekbrush; $\chi^{2}=15.2, d f=1, P<.0001$.

tional intervention. The baseline data also show awareness within the school community, resulting in a high prior knowledge level of TSD with students placing a high personal importance on genetic testing. Studies of other carrier screening programs, such as for CF, have suggested that teaching new and abstract concepts in genetics is difficult, particularly when existing public knowledge is limited. ${ }^{18,19}$ Contrary to these studies, the school community knowledge in the Melbourne TSD carrier screening program was high, even before education, prob- ably because of a continuously increasing awareness in this population. Although knowledge is an important outcome of an educational intervention, it is clear from the study described here that psychosocial and behavioral outcomes are equally, if not more, relevant in the decision-making process because they showed significant associations with student decisions.

Overall, the students' anxiety at the time of testing was not significantly different on the day of testing compared with before education. However, anxiety increased after education in 
2002, whereas it decreased in 2003. The greater level of anxiety on the day of testing in 2002 is likely because the test was a blood test rather than a cheekbrush test, as was offered in 2003. Education significantly decreased students' anxiety about being a carrier, which was also found in the Sydney TSD carrier screening program. ${ }^{16}$ These results support the suggestion that education is critical to screening programs in minimizing adverse psychosocial implications.

\section{Computer-based instruction is equally effective as oral educational interventions}

CBI resources have been shown to be equally effective as traditional instruction in many areas of genetics education, for population groups such as those at risk of an inherited cancer predisposing mutation ${ }^{20-22}$ and undergraduate students, ${ }^{23}$ and in the biology school curriculum. ${ }^{24}$ In this school-based TSD carrier screening program, the use of CBI is clearly equally as effective as the oral presentation for parameters measured not only on the day of testing but also 3 months later. This is the first report of CBI being used in a TSD carrier screening program. We previously discussed the added benefits of the use of CBI in educational sessions such as delivery of a consistent educational message, short delivery time, allowance of selfpaced learning, and minimum financial and resource commitment. ${ }^{15}$

\section{Cheekbrush sampling is preferred by students}

The availability of a sensitive and specific test that is acceptable to the community is one of the World Health Organization guidelines for the introduction of population screening. We found that cost is a barrier to the rate of testing uptake, and it was suggested that blood testing was also a barrier. ${ }^{14}$ This study has confirmed that this is the case with a significant increase in uptake and a decrease in anxiety when a cheekbrush test was offered as the alternative to blood sampling. Attitudes remain a powerful motivator for testing, with students having the cheekbrush being more favorable to genetic testing, and placing a greater personal importance on genetic testing than those declining a cheekbrush test. Other researchers who assessed the motivators for participation in the context of preconceptional carrier screening found that perceived discomfort as a factor based on the Health Belief Model ${ }^{25}$ was found to be significant in deterring participants from accepting a carrier test. ${ }^{26}$ However, in the context of TSD, there are suggestions that participation is not necessarily explained by the Health Belief Model. ${ }^{27}$ Despite this debate, the results described here support the finding that the discomfort of a blood test significantly reduced testing uptake rates.

The school setting offers a convenient place to conduct testing, giving a greater rate of testing uptake than other settings, which was shown to be the case in several settings. ${ }^{28-33}$ In fact, in the context of CF carrier screening in the adult population, rates of uptake increased with increasing convenience of testing, ${ }^{34-38}$ whereas a lack of time was the main reason for not participating. ${ }^{26}$ Convenience was cited as a reason for students accepting testing; however, the most common reason for test- ing was that they wanted to know, just as we ${ }^{14}$ and others have described. ${ }^{16}$

Although barriers such as costs and blood testing were removed, as well as maximizing convenience with on-site testing, a $100 \%$ uptake rate was not found. Those students declining testing most commonly did so because they did not want to know at that time in their life. Indeed, 3 months later, these students rated it very likely that they would be tested at some stage in the future.

This short-term evaluation of a TSD screening program found that education plays a critical role in allowing informed decisions about testing to be made and minimizing the psychosocial harms that possibly may arise. The offer of testing within schools provides a convenient setting, and cheekbrush sampling is able to significantly decrease participants' discomfort and anxiety about testing, which is a known testing deterrent. Establishing a well-executed program within a community is essential to the successful continuation as the community becomes familiar with the concepts and there is increasing acceptability. The CBI resource described here is equally effective as the traditional oral presentation in the context of schoolbased carrier screening for TSD. This has resource implications for the future continuation of the program and should reduce the cost and time commitment needed to deliver effective education.

\section{ACKNOWLEDGMENTS}

The authors acknowledge the valuable contributions made by the student participants of the TSD carrier screening program. We thank the participating school principals and staff for their help and cooperation. We also thank Anne Gason for her statistical advice. MBD is a recipient of an NHMRC Practitioner Fellowship.

\section{References}

1. Khoury MJ, McCabe LL, McCabe ER. Population screening in the age of genomic medicine. N Engl J Med 2003;348(1):50-58.

2. Kaback MM, Zeiger RS, Reynolds LW, Sonneborn M. Approaches to the control and prevention of Tay-Sachs disease. Prog Med Genet 1974;10:103-134.

3. Kaback MM, Nathan TJ, Greenwald S. Tay-Sachs disease: heterozygote screening and prenatal diagnosis. U.S. experience and world perspective. In: Kaback MM, ed. Tay-Sachs Disease, Screening and Prevention. New York: Alan R. Liss; 1997:13-36.

4. Omenn GS. Public health genetics: an emerging interdisciplinary field for the postgenomic era. Annu Rev Public Health 2000;21:1-13.

5. Clayton EW, Hannig VL, Pfotenhauer JP, Parker RA, et al. Teaching about cystic fibrosis carrier screening by using written and video information. Am J Hum Genet 1995;57(1):171-181.

6. Delvin E, Pottier A, Scriver CR, Gold RJ. The application of an automated hexosaminidase assay to genetic screening. Clin Chim Acta 1974;53(1):135-142.

7. Proia RL, Soravia E. Organization of the gene encoding the human beta-hexosaminidase alpha-chain. J Biol Chem 1987;262(12):5677-5681.

8. Myerowitz R, Costigan FC. The major defect in Ashkenazi Jews with Tay-Sachs disease is an insertion in the gene for the alpha-chain of beta-hexosaminidase. J Biol Chem 1988;263(35):18587-18589.

9. Myerowitz R. Splice junction mutation in some Ashkenazi Jews with Tay-Sachs disease: evidence against a single defect within this ethnic group. Proc Natl Acad Sci US A 1988;85(11):3955-3959.

10. Arpaia E, Dumbrille-Ross A, Maler T, Neote K, et al. Identification of an altered splice site in Ashkenazi Tay-Sachs disease. Nature 1988;333(6168):85-86.

11. Navon R, Proia RL. The mutations in Ashkenazi Jews with adult GM2 gangliosidosis, the adult form of Tay-Sachs disease. Science 1989;243(4897):1471-1474. 


\section{Gason et al}

12. Fernandes MJ, Kaplan F, Clow CL, Hechtman P, et al. Specificity and sensitivity of hexosaminidase assays and DNA analysis for the detection of Tay-Sachs disease gene carriers among Ashkenazic Jews. Genet Epidemiol 1992;9(3):169-175.

13. Bach G, Tomczak J, Risch N, Ekstein J. Tay-Sachs screening in the Jewish Ashkenazi population: DNA testing is the preferred procedure. Am J Med Genet 2001;99(1): $70-75$.

14. Gason AA, Sheffield E, Bankier A, Aitken MA, et al. Evaluation of a Tay-Sachs disease screening program. Clin Genet 2003;63 (5):386-392.

15. Gason AA, Aitken M, Delatycki MB, Sheffield E, et al. Multimedia messages in genetics: design, development, and evaluation of a computer-based instructional resource for secondary school students in a Tay Sachs disease carrier screening program. Genet Med 2004;6(4):226-231.

16. Barlow-Stewart K, Burnett L, Proos A, Howell V, et al. A genetic screening programme for Tay-Sachs disease and cystic fibrosis for Australian Jewish high school students. J Med Genet 2003;40(4):e45.

17. Marteau TM, Bekker H. The development of a six-item short-form of the state scale of the Spielberger State-Trait Anxiety Inventory (STAI). Br J Clin Psychol 1992; 31(3):301-306.

18. Decruyenaere M, Evers-Kiebooms G, Denayer L, Van den Berghe H. Cystic fibrosis: community knowledge and attitudes towards carrier screening and prenatal diagnosis. Clin Genet 1992;41 (4):189-196.

19. Henneman L, Poppelaars FA, Ten Kate LP. Evaluation of cystic fibrosis carrier screening programs according to genetic screening criteria. Genet Med 2002;4 (4): 241-249.

20. Jones JM, Nyhof-Young J, Friedman A, Catton P. More than just a pamphlet: development of an innovative computer-based education program for cancer patients. Patient Educ Couns 2001;44(3):271-281.

21. Green MJ, Biesecker BB, McInerney AM, Mauger D, et al. An interactive computer program can effectively educate patients about genetic testing for breast cancer susceptibility. Am J Med Genet 2001;103(1):16-23.

22. Green MJ, McInerney AM, Biesecker BB, Fost N. Education about genetic testing for breast cancer susceptibility: patient preferences for a computer program or genetic counselor. Am J Med Genet 2001;103(1):24-31.

23. Miedzybrodzka Z, Hamilton NM, Gregory H, Milner B, et al. Teaching undergraduates about familial breast cancer: comparison of a computer assisted learning (CAL) package with a traditional tutorial approach. Eur J Hum Genet 2001;9(12):953-956.

24. Morrell PD. The effects of computer assisted instruction on student achievement in high school biology. Sch Sci Math 1992;92(4):177-181.
25. Rosenstock IM. Why people use health services. Milbank Mem Fund Q 1966;44:94127.

26. Henneman L, Bramsen I, Van der Ploeg HM, Ader HJ, et al. Participation in preconceptional carrier couple screening: characteristics, attitudes and knowledge of both partners. J Med Genet 2001;38:695-703

27. Goldstein MS, Greenwald S, Nathan T, Massariki F, et al. Health behaviour and genetic screening for carriers of Tay-Sachs disease-a prospective study. Soc Sci Med 1977;11:515-520.

28. Beck E, Blaichman S, Scriver CR, Clow CL. Advocacy and compliance in genetic screening. Behavior of physicians and clients in a voluntary program of testing for the Tay-Sachs gene. N Engl J Med 1974;291(22):1166-1170.

29. McCabe L. Efficacy of a targeted genetic screening program for adolescents. Am J Hum Genet 1996;59(4):762-763.

30. Mitchell J, Scriver CR, Clow CL, Kaplan F. What young people think and do when the option for cystic fibrosis carrier testing is available. J Med Genet 1993;30(7):538542 .

31. Mitchell JJ, Capua A, Clow C, Scriver CR. Twenty-year outcome analysis of genetic screening programs for Tay-Sachs and beta-thalassemia disease carriers in high schools. Am J Hum Genet 1996;59(4):793-798.

32. Motulsky AG. Screening for genetic diseases. N Engl J Med 1997;336(18):1314-1316

33. Rozenberg R, Pereira L. The frequency of Tay-Sachs disease causing mutations in the Brazilian Jewish population justifies a carrier screening program. Sao Paulo Med J 2001;119(4):146-149.

34. Clayton EW, Hannig VL, Pfotenhauer JP, Parker RA, et al. Lack of interest by nonpregnant couples in population-based cystic fibrosis carrier screening. Am J Hum Genet 1996;58(3):617-627.

35. Payne Y, Williams M, Cheadle J, Stott NC, et al. Carrier screening for cystic fibrosis in primary care: evaluation of a project in South Wales. The South Wales Cystic Fibrosis Carrier Screening Research Team. Clin Genet 1997;51(3):153-163.

36. Bekker H, Modell M, Denniss G, Silver A, et al . Uptake of cystic fibrosis testing in primary care: supply push or demand pull? BMJ 1993;306 (6892):1584-1586.

37. Tambor ES, Bernhardt BA, Chase GA, Faden RR, et al. Offering cystic fibrosis carrie screening to an HMO population: factors associated with utilization. Am J Hum Genet 1994;55(4):626-637.

38. Watson EK, Mayall E, Chapple J, Dalziel M, et al. Screening for carriers of cystic fibrosis through primary health care services. BMJ 1991;303:504-507. 